\title{
Tree-ring radiocarbon reveals reduced solar activity during Younger Dryas cooling
}

\section{Other Conference Item}

\section{Author(s):}

Sookdeo, Adam; Kromer, Bernd; Adolphi, Florian; Beer, Jürg; Brehm, Nicolas; Büntgen, Ulf; Christl, Marcus; Eglinton, Timothy I.; Friedrich, Michael; Guidobaldi, Giulia; Helle, Gerd; Muscheler, Raimund; Nievergelt, Daniel; Pauly, Maren; Reinig, Frederick; Tegel, Willy; Treydte, Kerstin; Turney, Chris; Synal, Hans-Arno (iD; Wacker, Lukas

\section{Publication date:}

2020-05-08

Permanent link:

https://doi.org/10.3929/ethz-b-000456961

\section{Rights / license:}

Creative Commons Attribution 4.0 International

Originally published in:

EGUsphere, https://doi.org/10.5194/egusphere-egu2020-11654 
EGU2020-11654

https://doi.org/10.5194/egusphere-egu2020-11654

EGU General Assembly 2020

(c) Author(s) 2020. This work is distributed under

the Creative Commons Attribution 4.0 License.

\title{
Tree-ring radiocarbon reveals reduced solar activity during Younger Dryas cooling
}

\author{
Adam Sookdeo 1,2 , Bernd Kromer ${ }^{3}$, Florian Adolphi ${ }^{4,5}$, Jürg Beer $^{6}$, Nicolas Brehm², Ulf Büntgen ${ }^{7,8,9}$, \\ Marcus Christl ${ }^{2}$, Timothy Eglinton ${ }^{10}$, Micheal Friedrich ${ }^{3,11}$, Giulia Guidobaldi ${ }^{2}$, Gerd Helle ${ }^{12}$, Raimund \\ Muscheler ${ }^{5}$, Daniel Nievergelt ${ }^{8}$, Maren Pauly ${ }^{13}$, Frederick Reinig ${ }^{8,14}$, Willy Tegel ${ }^{15}$, Kerstin Treydte ${ }^{8}$, \\ Chris Turney ${ }^{2,16}$, Hans-Arno Synal ${ }^{2}$, and Lukas Wacker ${ }^{2}$ \\ ${ }^{1}$ UNSW, Analytical Chemistry, Chronos 14Carbon-Cycle Facility, Sydney, Australia (a.sookdeo@unsw.edu.au) \\ ${ }^{2}$ ETH-Zürich, Laboratory of Ion Beam Physics, Zürich, Switzerland \\ ${ }^{3}$ Heidelberg University, Institute of Environmental Physics, Heidelberg, Germany \\ ${ }^{4}$ University of Bern, Climate and Environmental Physics \& Oeschger Center for Climate Change Research, Bern, Switzerland \\ ${ }^{5}$ Lund University, Department of Geology-Quaternary Sciences, Lund, Sweden \\ ${ }^{6}$ Swiss Federal Institute of Aquatic Science and Technology EAWAG, Zürich, Switzerland \\ ${ }^{7}$ Swiss Federal Research Institute WSL, Birmensdorf, Switzerland \\ ${ }^{8}$ University of Cambridge, Department of Geography, Cambridge, UK \\ ${ }^{9}$ University Brno, Global Change Research Institute CAS and Masaryk, Brno, Czech Republic \\ ${ }^{10}$ ETH-Zurich, Carbon Cycle Biogeoscience, Zürich, Switzerland \\ ${ }^{11}$ Hohenheim University, Institute of Botany, Stuttgart, Germany \\ ${ }^{12}$ GFZ German Research Centre for Geosciences, Potsdam, Germany \\ ${ }^{13}$ Bath Spa Univerisity, School of Science, Bath, UK \\ ${ }^{14}$ University Mainz, Department of Geography, Johannes Gutenberg, Germany \\ ${ }^{15}$ Albert-Ludwigs University of Freiburg, Freiburg, Germany \\ ${ }^{16}$ Palaeontology, Geobiology and Earth Archives Research Centre (PANGEA), University of New South Wales, Sydney, \\ Australia
}

The Younger Dryas stadial (YD) was a return to glacial-like conditions in the North Atlantic region that interrupted deglacial warming around $12900 \mathrm{cal}$ BP (before 1950 AD). Terrestrial and marine records suggest this event was initiated by the interruption of deep-water formation arising from North American freshwater runoff, but the causes of the millennia-long duration remain unclear. To investigate the solar activity, a possible YD driver, we exploit the cosmic production signals of tree-ring radiocarbon $\left({ }^{14} \mathrm{C}\right)$ and ice-core beryllium-10 $\left({ }^{10} \mathrm{Be}\right)$. Here we present the highest temporally resolved dataset of ${ }^{14} \mathrm{C}$ measurements $(n=1558)$ derived from European tree rings that have been accurately extended back to $14226 \mathrm{cal} B P( \pm 8,2-\sigma)$, allowing precise alignment of ice-core records across this period. We identify a substantial increase in ${ }^{14} \mathrm{C}$ and ${ }^{10} \mathrm{Be}$ production starting at 12780 cal BP is comparable in magnitude to the historic Little Ice Age, being a clear sign of grand solar minima. We hypothesize the timing of the grand solar minima provides a significant amplifying factor leading to the harsh sustained glacial-like conditions seen in the YD. 